\title{
Life cycle versus balanced funds: An emerging market perspective
}

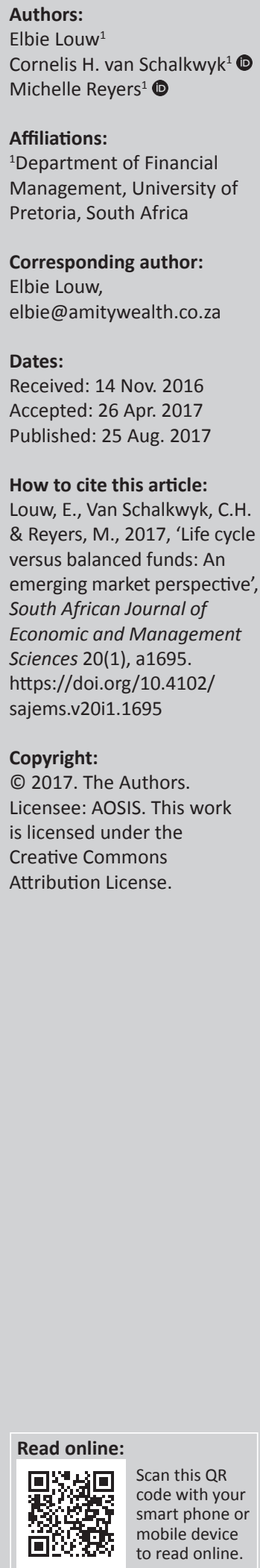

Background: Inadequate retirement savings is an international challenge. Additionally, individuals are not cognisant of how asset allocation choices ultimately impact retirement savings. Life cycle and balanced funds are popular asset allocation strategies to save towards retirement. However, recent research is questioning the efficacy of life cycle funds that switch to lower risk asset classes as retirement approaches.

Aim: The purpose of this study is to compare the performance of life cycle funds with balanced funds to determine whether either dominates the other. The study compares balanced and life cycle funds with similar starting asset allocations as well as those where the starting asset allocations differ.

Setting: The study has a South African focus and constructs funds using historical data for the main local asset classes; that is, equity, fixed income and cash, as well as a proxy for foreign equity covering the period 1986-2013.

Method: The study makes use of Monte Carlo simulations and bootstrap with replacement, and compares the simulated outcomes using stochastic dominance as decision-making criteria.

Results: The results indicate that life cycle funds fail to dominate balanced funds by first-order or almost stochastic dominance when funds have a similar starting asset allocation. It is noteworthy that there are instances where the opposite is true, that is, balanced funds dominate life cycle funds. These results highlight that while the life cycle funds provide more downside protection, they significantly supress the upside potential compared to balanced funds. When the starting asset allocations of the balanced and life cycle funds differ, the stochastic dominance results are inconsistent as to the efficacy of the life cycle fund strategies considered.

Conclusion: The study shows that whether one fund is likely to dominate the other is strongly dependent on the underlying asset allocation strategies of the funds. Additionally, the length of the glide path and the risk and return characteristics of the investable universe are also likely to influence the findings.

\section{Introduction}

The potential inadequacy of accumulated retirement wealth is a global dilemma. The National Institute on Retirement Savings (2013) estimates that, should one consider formal retirement savings of households only, $92 \%$ of American households will fall short of their retirement targets while the Department for Work and Pensions (2012) estimates that 38\% of the United Kingdom's workforce will not be adequately prepared for retirement.

Despite 5143 retirement funds registered in South Africa which covers approximately 16 million members in 2015, it is estimated that only $6 \%$ to $10 \%$ of South Africans are saving sufficiently for retirement (Financial Services Board 2015a; Jones 2011; Old Mutual in Kemp 2005). Similar to other countries, the retirement funds in South Africa are predominantly defined contribution pension funds, which have significant implications for members who must participate in the investment decision-making process and who ultimately end up bearing the investment risks related to these decisions (Financial Services Board 2015a, 2015b; Levitan and Merton 2015). In a defined contribution retirement fund, the retirement benefit received by a participant upon retirement is not guaranteed and depends on the performance of financial markets. The individual bears the investment risk of the fund, and the plan often shifts a significant number of decisions such as the asset mix as well as how much to invest from the plan sponsor to the participant as is the case in a member-directed plan (Thaler and Benartzi 2007). In contrast, a defined benefit retirement fund refers to a fund for which the retirement benefit received by an individual upon retirement is guaranteed, irrespective of how financial markets perform, and determined by a 
formula which usually considers an individual's ending salary and years of service (Bodie, Marcus \& Merton 1988). As this study focuses on asset allocation strategies, it is only applicable to defined contribution plans.

In terms of the allowable range of asset mixes, Regulation 28 of the Pension Funds Act dictates maximum exposures that a South African retirement fund may have to particular investable asset classes and, in certain instances, the acceptable selections within a particular asset class (National Treasury of South Africa 2011). Importantly, the higher return, higher risk equity asset class is restricted to a maximum of $75 \%$ of the overall asset allocation with the allocation to foreign asset classes limited to 25\% (National Treasury of South Africa 2011). However, within the limits provided by Regulation 28 there are a wide variety of different asset mixes and asset allocation strategies, which members of defined contribution plans need to choose between which impact on their accumulated retirement wealth.

Many individuals are not cognisant of how the asset allocation of their chosen retirement savings vehicle and the consequential risk and return characteristics can influence the likelihood of reaching an accumulated retirement wealth target to sustain their post-retirement years or how different asset allocation strategies compare to one another. The importance of the asset allocation choice is further highlighted by Brinson, Hood and Beebower (1986) in that 93.6\% of the variation of portfolio performance over time can be explained by the asset allocation. To help participants of defined contribution funds with some of the choices they have to make, plan sponsors often offer default options within the retirement fund to add some assistance to individuals with regard to appropriate investment choices (Levitan and Merton 2015). To this end, much research, using US data, has been devoted to comparing life cycle and balanced funds to determine, which approach provides a superior outcome (Basu, Byrne \& Drew 2011; Estrada 2014; Lewis 2008a, 2008b, 2008c; Spitzer and Singh 2011).

There has been limited research regarding retirement savings decisions in South Africa and research that has been carried out has focused on understanding retirement adequacy goals and behavioural influences on retirement savings decisions (Reyers et al. 2015; Van Zyl and Van Zyl 2016). Only a limited number of studies have considered asset allocation strategies in a South African context with the focus varying from evaluating the impact of including foreign investments, comparing post-retirement investment choices, a comparison of default choices offered by retirement funds and the impact on portfolio optimisation based on an efficient frontier (De Villiers-Strydom and Krige 2014; Levitan and Merton 2015; Mjebeza 2016; Van Heerden and Koegelenberg 2013). Although valuable, none of these studies address the life cycle versus balanced fund question or apply the decisionmaking criteria stochastic dominance (SD). The objective of this study is to make use of the SD decision-making criteria to provide additional insights into the debate concerning life cycle versus balanced funds. In addition, the study adds to the literature by providing a developing world perspective by using South African data.

\section{Life cycle versus balanced funds}

While balanced or target risk funds maintain a constant asset allocation strategy throughout the investment horizon, Basu et al. (2011) describe life cycle or target date funds as funds where the assets are moved from higher risk to lower risk asset classes as the individual advances towards retirement in an attempt to preserve retirement ending wealth and offer downside protection (also see Branch and Qiu 2011; Lewis 2008b, 2008c; Spitzer and Singh 2011). Both mutual funds with a life cycle structure and pension fund life cycle funds have, therefore, become popular in the retirement fund offering because the individual does not have to make the asset allocation and switching decisions (with the intent to preserve capital) as the fund does so automatically - his or her only decision is choosing the appropriate life cycle fund given his or her expected retirement date (Basu and Drew 2009; Basu et al. 2011; Estrada 2014; Lewis 2008a, 2008b, 2008c; Spitzer and Singh 2008, 2011).

Much of the body of knowledge is devoted to consider how different balanced fund asset allocation strategies and life cycle fund asset allocation strategies fair as well as to critically compare the efficacy of traditional life cycle versus balanced funds. Importantly, Estrada (2014) highlights that the debates on the most optimal asset allocation strategy may be nestled in how risk is defined. Some may view a low-risk fund as a stable investment with little adverse shocks while an alternative view may be that a low-risk fund is the fund, which provides the highest mean accumulated ending wealth (Lewis 2008c; Shiller 2006). Should 'risk' be interpreted as a greater range exhibited by the outcomes, the balanced funds would be a riskier choice.

Research specifically related to life cycle funds carried out by Lewis (2008b) focuses on the replacement ratio that can be achieved by different life cycle strategies namely a conservative, moderate and aggressive strategy and includes the interquartile range as an indication of the risk of each strategy. The median replacement ratio for each strategy is $0.38,0.36$ and 0.33 , respectively; however, the interquartile range of the replacement ratio for each portfolio offers valuable insights. For the aggressive portfolio, the range is 0.30 to 0.52 , for the moderate portfolio 0.29 to 0.46 and for the conservative portfolio 0.27 to 0.41 . The results highlight the issue of how an individual views retirement wealth risk; if shortfall risk during retirement is perceived as being a greater risk, more aggressive strategies with higher allocations to equity might be preferable where the shortfall refers to accumulating less wealth than what was required at retirement.

In Lewis (2008a), the focus shifts to shortfall risk in determining the efficacy of life cycle fund strategies. He acknowledges that the intent of life cycle funds is to lower the likelihood of potential losses by decreasing the allocation to 
risky assets as retirement approaches. The three life cycle funds modelled exhibit a $34.7 \%$ (aggressive), $43.8 \%$ (moderate) and $58.6 \%$ (conservative) probability of shortfall for an income replacement ratio of 0 to 0.5 . Hence an individual who invests in the aggressive portfolio and pursues an income replacement ratio of 0.5 has a $34.7 \%$ probability of shortfall. Based on this approach, a higher allocation to low-risk asset classes may not be optimal despite the lower short-term volatility of the portfolio.

The research of Schleef and Eisinger (2007) compares different life cycle and balanced fund strategies and the chances of meeting a retirement target. The researchers conclude that strategies weighted towards equities still have a better chance of achieving the retirement target and that for all the simulated portfolios (life cycle and balance funds) there is more than a $50 \%$ chance of failing to meet the retirement target. Balanced funds with an asset allocation to equities of $70 \%$ or more are superior to all other portfolios, including an aggressive life cycle portfolio, in achieving the retirement target; the $100 \%$ equity portfolio has only a $39 \%$ chance of not meeting the target (Schleef and Eisinger 2007). Byrne et al. (2006) follow suit by comparing how a balanced fund $(60 \%$ equity, $40 \%$ bonds) and a life cycle fund (100\% equity minus the individual's age over the investment horizon) impact accumulated retirement ending wealth. The life cycle fund offers a higher mean replacement ratio irrespective of the investment horizon. In contrast, the results of Spitzer and Singh (2011) indicated that neither of the life cycle portfolios modelled outperformed a balanced portfolio with an allocation to equities of equal to or greater than $80 \%$, and all the models exhibited right-skewness (the mean exceeding the median) similar to the findings of Pfau (2010). Importantly, Spitzer and Singh (2011) focus on achieving the highest mean ending wealth and do not consider the range of possible outcomes or the risk exhibited by each strategy. The studies highlight that the beginning and ending equity allocations over the investment horizon along with how aggressive the glide path is, are important factors which determine the success of a life cycle strategy. A valuable conclusion drawn by Basu and Drew (2009) is that life cycle strategies that commence with a glide path early in the investment horizon are better at protecting downside risk. There also seems to be a diminishing risk reduction benefit for life cycle strategies that defer switching to more conservative asset classes.

Lewis (2008c) also compared balanced funds with life cycle funds [similar to Spitzer and Singh (2011)] using similar life cycle strategies as in his previous research. Focusing on the proportion of final salary that could be obtained from the accumulated retirement wealth, the aggressive portfolio exhibits the highest standard deviation and widest range of proportion of final salary with the conservative portfolio exhibiting the lowest risk (standard deviation and range). Lewis (2008c) subsequently infers the average asset allocation to equity within each life cycle portfolio and simulates three comparable balanced funds. The results reveal the following: The average percentage of retirement salary which could be achieved by each of the resulting three portfolios is consistently higher for the balanced funds (Lewis 2008c). Furthermore, the kurtosis of the life cycle funds is consistently slightly higher than that of the comparable balanced funds (Lewis 2008c).

Pfau (2010) also makes a strong case in support of life cycle funds by focusing on the risk-return trade-off between more aggressive balanced funds and the protection offered by life cycle funds. His research introduces a utility function that captures the risk aversion of the individual and how this may alter one's interpretation of which strategy is optimal. Without considering investor utility, the life cycle strategies modelled by Pfau (2010) slightly underperform the balanced fund strategies with a similar average equity exposure.

Basu et al. (2011) introduced an innovative alternative to the traditional life cycle fund; the dynamic approach proposed considers the retirement target and the asset class returns achieved to date and only switches to lower risk asset classes on the condition that the retirement target may realistically be achieved based on the accumulated wealth at every stage of switching, therefore, considering the impact of past market performance and future return expectations. Basu et al. (2011) contend that although the traditional life cycle strategy may be appropriate to protect the downside risk of the portfolio closer to retirement, it may fail to realise the retirement wealth target.

The results of Basu et al. (2011) indicate that the dynamic life cycle strategies seem superior to traditional life cycle funds, irrespective of how long the glide path is. It also offers better downside protection and mean accumulated wealth compared with a balanced fund. Likewise, the higher the allocation to equities in a balanced fund, the better the mean wealth accumulation. The riskiness of the strategy as measured by range, distribution and standard deviation increases with the equity allocation.

The literature presents life cycle funds that start and end with varying exposures to equity and diverse periods over which the glide path is implemented. These factors make it difficult to generalise about the performance of these funds. However, the majority of literature indicates that, generally, a balanced fund with an average asset allocation over the investment horizon, which is similar to that of a life cycle counterpart, offers a higher mean retirement accumulation and wider range, distribution and standard deviation (Lewis 2008c). This general finding has been challenged by Pang and Warshawsky (2011), who acknowledged that balanced funds exhibited a wider range, distribution and standard deviation but indicated that, in their research, the mean accumulated ending wealth for balanced and life cycle funds was quite similar.

\section{Research method Life cycle and balanced fund models}

Four balanced funds (BF) and life cycle funds (LC) each are considered. The four balanced funds $\left(\mathrm{BF}_{1}\right.$ to $\left.\mathrm{BF}_{4}\right)$ each have a unique asset allocation strategy as detailed in Table 1. 
TABLE 1: Balanced and life cycle funds modelled.

\begin{tabular}{llll}
\hline Model & Balanced/Life cycle fund & Starting asset allocation $\dagger$ & Ending asset allocation $\dagger$ \\
\hline $\mathrm{BF}_{1}$ & Low equity balanced fund & $15 / 25 / 50 / 10$ & $15 / 25 / 50 / 10$ \\
$\mathrm{BF}_{2}$ & Medium equity balanced fund & $35 / 25 / 30 / 10$ & $35 / 25 / 30 / 10$ \\
$\mathrm{BF}_{3}$ & High equity balanced fund & $75 / 0 / 15 / 10$ & $75 / 0 / 15 / 10$ \\
$\mathrm{BF}_{4}$ & High equity balanced fund & $50 / 25 / 15 / 10$ & $50 / 25 / 15 / 10$ \\
$\mathrm{LC}_{1(10)}$ & Life cycle & $75 / 0 / 15 / 10$ & $0 / 0 / 0 / 100$ \\
$\mathrm{LC}_{1(5)}$ & Life cycle & $75 / 0 / 15 / 10$ & $0 / 0 / 0 / 100$ \\
$\mathrm{LC}_{2(10)}$ & Life cycle & $50 / 25 / 15 / 10$ & $10 / 0 / 0 / 100$ \\
$\mathrm{LC}_{2(5)}$ & Life cycle & $50 / 25 / 15 / 10$ & 5 years \\
\hline
\end{tabular}

$\dagger$, Shown as percentage allocated to local equity/foreign equity/local fixed income/local cash, respectively.

In the case of the life cycle funds, two contrasting starting asset allocations are considered $\left(\mathrm{LC}_{1}\right.$ vs. $\left.\mathrm{LC}_{2}\right)$, as well as different glide paths over 10 and 5 years, respectively (contrast $\mathrm{LC}_{1(10)}$ with $\left.\mathrm{LC}_{1(5)}\right)$. In all instances, the funds modelled comply with the requirements of Regulation 28 of the Pension Fund Act. The asset allocations and glide paths (where applicable) for all funds modelled are shown in Table 1.

In comparing traditional LC funds with $\mathrm{BF}$, the research considers a South African resident that saves for retirement from age 25 to 65 (a 40-year investment horizon) and earns a starting salary of R673 101 (South African Rand). The individual's salary annually increases at a rate of inflation of $4.5 \%$. Throughout the pre-retirement investment horizon, the individual contributes $15 \%$ of the annual salary to a retirement fund while the contributions are made at the end of each month. This implies that the individual makes 480 monthly contributions. Furthermore, the individual is assumed to be in the workforce for the full 40-year investment horizon.

All the funds modelled are rebalanced annually similar to other studies (Basu and Drew 2009; Lewis 2008c; Pfau 2011; Schleef and Eisinger 2007; Spitzer and Singh 2011) either to the original static asset allocation in the case of $\mathrm{BF}$ or, in the case of LC funds, the static asset allocation in the earlier years and then, during the glide path, in the manner necessary to ensure a linear reduction in the higher risk asset classes over the glide path period at the beginning of the year that it applies to.

\section{Simulating accumulated retirement ending wealth values}

To simulate the accumulated retirement ending wealth values, the study uses SAS statistical software to programme each model based on the general and model-specific assumptions highlighted in the previous section. By means of Monte Carlo simulation and bootstrap with replacement, the simulation trial of each model is iterated 10000 times resulting in 10000 nominal accumulated retirement ending wealth values for each model. Secondary historical financial market data from reputable data providers and peerreviewed research studies are used for the simulations.

Monte Carlo simulation is favoured for the analysis because of the intrinsic statistical independence it exhibits when compared to other estimation models (Ervin, Faulk \& Smolira 2009).With regard to bootstrapping with replacement, the method follows a random draw with replacement from the empirical distribution of asset class returns. The historical monthly return data for every asset class are randomly resampled with replacement to create asset class return vectors for each period (i.e. each month). Because the resampling is done with replacement, a particular data point from the original data set can appear multiple times in a given bootstrap sample (Basu et al. 2011). The bootstrapping results in vectors of asset class returns from the same time period, which maintains the correlation between the different asset class returns (Branch and Qiu 2011). It is assumed that the returns of individual asset classes are independently distributed over time (Basu and Drew 2009).

\section{Historical data}

The study uses monthly data from the period January 1986 to December 2013, that is, 336 historical monthly data points for each asset class. From January 1986 to December 2000, the local asset class data were provided by Staunton (2013) as per Firer and McLeod (1999) and Firer and Staunton (2002). Data from 2001 to 2013 were constructed by applying the return calculation method used by Firer and Staunton (2002) and using the Alexander Forbes Short-term Fixed Interest Index (STeFi) for the money market asset class, FTSE/JSE All Bond Index (ALBI) for the fixed income asset class and FTSE/JSE All Share Index (ALSI) for the equity asset class. The Firer and Staunton (2002) database does not include a foreign equity asset class and so the MSCI World index is used as a proxy for the foreign equity asset class from January 1986 to December 2013. The total return descriptive statistics for each asset class are shown in Table 2. It is acknowledged that historical data are not necessarily reflective of future expected returns and that the data period and data set used may influence the results.

\section{Stochastic dominance decision-making criteria}

Similar to Basu et al. (2011), the study uses the cumulative distribution function of the accumulated retirement ending wealth and the principle of SD to compare LC and BF. SD is the most general approach to decision-making under uncertain circumstances (Levy 2009). Additionally, SD can be employed irrespective of whether the distributions of the choices under consideration are normally distributed or not (Basu et al. 2011; Levy 2009). First-degree stochastic dominance (FSD) assumes that the utility function of the decision-maker $U(x)$ increases with $x, U^{\prime}(x)>0$. Therefore, the decision-maker 
prefers more of $x$ rather than less (Graves and Ringuest 2009), with $x$ being the metric that the decision is related to whether return or wealth.

Assuming two portfolios, namely A and B, an individual would prefer Portfolio A over B under FSD if:

$\mathrm{F}_{\mathrm{B}}(\mathrm{x}) \geq \mathrm{F}_{\mathrm{A}}(\mathrm{x})$

For all values of $\mathrm{x}$.

With:

$\mathrm{F}_{\mathrm{B}}(\mathrm{x})=$ Cumulative probability distribution of $\mathrm{B}$

$\mathrm{F}_{\mathrm{A}}(\mathrm{x})=$ Cumulative probability distribution of $\mathrm{A}$

This implies that A will dominate B if the cumulative probability distribution of $B$ is always below or to the right of that of A (Graves and Ringuest 2009). Almost stochastic dominance (ASD) relaxes this strict assumption because it does not require that the cumulative probability distribution of $\mathrm{B}$ always must be below that of $\mathrm{A}$ to dominate by ASD. However, the relaxation of this assumption is conditional: The area of violation (i.e. the area where the cumulative probability distribution of $B$ is above that of A) must be very small compared with the total area of the two distributions (Basu et al. 2011; Levy 2009, 2012). The SD decision-making criteria consider both risk and potential outcomes with the cumulative distribution function. Additionally, if the cumulative distribution function of a model is steeper relative to another, the strategy is generally considered to result in less volatile outcomes (Basu et al. 2011). Where there is no clear indication of FSD for one model against the other, the study applies a similar conservative rule that if $\varepsilon$, the area of violation, is between 0 and 0.01 , one can accept dominance by ASD. This implies that one of three outcomes is possible: A may dominate B, neither A nor B may dominate, or B may dominate A by ASD.

\section{Empirical results}

The distribution functions of all the model simulated outcomes are positively skewed (i.e. exhibit right-skewness) with means higher than the median and skewness values above 0 . All the models exhibit leptokurtic distributions as the kurtosis values are positive.

\section{Funds with similar starting asset allocations}

To consider the potential SD of life cycle funds versus balanced funds with similar starting asset allocations, the $\varepsilon$ values of models $\mathrm{LC}_{1(10)}$ and $\mathrm{LC}_{1(5)}$ versus model $\mathrm{BF}_{3}$ as well as models $\mathrm{LC}_{2(10)}$ and $\mathrm{LC}_{2(5)}$ versus model $\mathrm{BF}_{4}$ were determined. The comparative cumulative distribution functions (log scale, with a base of 10) are shown in Figures 1 and 2 with the ASD results shown in Table 3.

In Figure 1, the cumulative distribution functions of model $\mathrm{LC}_{1(10)}$ and $\mathrm{LC}_{1(5)}$ cross that of model $\mathrm{BF}_{3^{\prime}}$ violating the strict FSD principles. The cumulative distribution functions of $\mathrm{LC}_{1(10)}$ cross $\mathrm{BF}_{3}$ at an accumulated ending wealth value of approximately R113.7 million. To the left of R113.7 million, the cumulative distribution function of $\mathrm{LC}_{1(10)}$ is below or to the right of $\mathrm{BF}_{3^{\prime}}$ therefore for an accumulated retirement ending wealth value below R113.7 million, an individual should prefer $\mathrm{LC}_{1(10)}$ as this model is likely to achieve a higher accumulated retirement ending wealth for each cumulative probability versus $\mathrm{BF}_{3}$. However, an individual with a retirement target of more than R113.7 million should prefer $\mathrm{BF}_{3}$ as, in these instances the cumulative distribution function of $\mathrm{BF}_{3}$ is below or to the right of $\mathrm{LC}_{1(10)}$. However, because the area enclosed by the cumulative distribution functions which is to the right of R113.7 is much larger than the area enclosed to the left, the cumulative distribution functions indicate that $\mathrm{BF}_{3}$ is more likely to dominate $\mathrm{LC}_{1(10)}$ by ASD if the $\varepsilon$ value is between 0 and 0.01 .

Also in Figure 1, the cumulative distribution functions of $\mathrm{LC}_{1(5)}$ cross $\mathrm{BF}_{3}$ at an accumulated ending wealth value of

TABLE 2: Descriptive statistics of nominal total monthly returns of local and foreign asset classes (1986-2013).

\begin{tabular}{lllll}
\hline Measure & Foreign equity (in ZAR) $\dagger$ & Local equity (in ZAR) & Local fixed income (in ZAR) & Local money market (in ZAR) \\
\hline Median & $1.21 \%$ & $1.85 \%$ & $1.26 \%$ & $0.90 \%$ \\
Arithmetic mean & $1.23 \%$ & $1.49 \%$ & $1.19 \%$ & $0.95 \%$ \\
Geometric mean & $1.11 \%$ & $1.32 \%$ & $1.16 \%$ & $0.95 \%$ \\
Minimum return & $-19.59 \%$ & $-29.71 \%$ & $-14.46 \%$ & $0.39 \%$ \\
Maximum return & $18.96 \%$ & $17.76 \%$ & $11.41 \%$ & $2.43 \%$ \\
Standard deviation & $5.02 \%$ & $5.72 \%$ & 336 & $0.34 \%$ \\
Observations & 336 & 336 & 336 \\
\hline
\end{tabular}

$\dagger$, For comparison, the returns are reported in ZAR. However, in the modelling, the USD return and applicable ZAR/USD exchange rate are used (as per the applicable vector). Source: Provided by Staunton (2013) and calculated from Morningstar.

TABLE 3: ASD results of life cycle funds against balanced funds - similar starting asset allocation.

\begin{tabular}{|c|c|c|c|c|c|c|c|}
\hline \multirow[t]{2}{*}{ Model } & \multirow[t]{2}{*}{ Balanced fund model } & \multirow{2}{*}{$\begin{array}{l}\text { Beginning asset } \\
\text { allocation } \dagger(\%)\end{array}$} & \multirow{2}{*}{$\begin{array}{c}\text { Glide path } \\
\text { period (years) }\end{array}$} & \multicolumn{4}{|c|}{ Area of SD violation relative to non-violation $(\varepsilon) \$$ : Life cycle fund model } \\
\hline & & & & $\begin{array}{l}\mathrm{LC}_{1(10)}(75 / 0 / 15 / 10, \\
10 \text {-year glide path) }\end{array}$ & $\begin{array}{l}\mathrm{LC}_{1(5)}(75 / 0 / 15 / 10, \\
5 \text {-year glide path) }\end{array}$ & $\begin{array}{l}\mathrm{LC}_{2(10)} 50 / 25 / 15 / 10, \\
10 \text {-year glide path) }\end{array}$ & $\begin{array}{c}\mathrm{LC}_{2(5)}(50 / 25 / 15 / 10, \\
5 \text {-year glide path) }\end{array}$ \\
\hline $\mathrm{BF}_{3}$ & $\begin{array}{l}\text { Balanced high equity } \\
\text { (no foreign exposure) }\end{array}$ & $75 / 0 / 15 / 10$ & N/A & $1111.1111 \S$ & $1666.6667 \S$ & - & - \\
\hline $\mathrm{BF}_{4}$ & $\begin{array}{l}\text { Balanced high equity ( } 25 \% \\
\text { foreign equity exposure) }\end{array}$ & $50 / 25 / 15 / 10$ & N/A & - & - & 97.0874 & $128.2051 \S$ \\
\hline
\end{tabular}

$\dagger$, Local equity/foreign equity/local fixed income/local money market; $\uparrow$, Almost stochastic dominance exists for threshold value of $0<\varepsilon<0.01 ; \S$, The balanced fund model dominates the life cycle fund model by FSD if $\varepsilon$ value shows 'No value' or ASD in all other cases. 


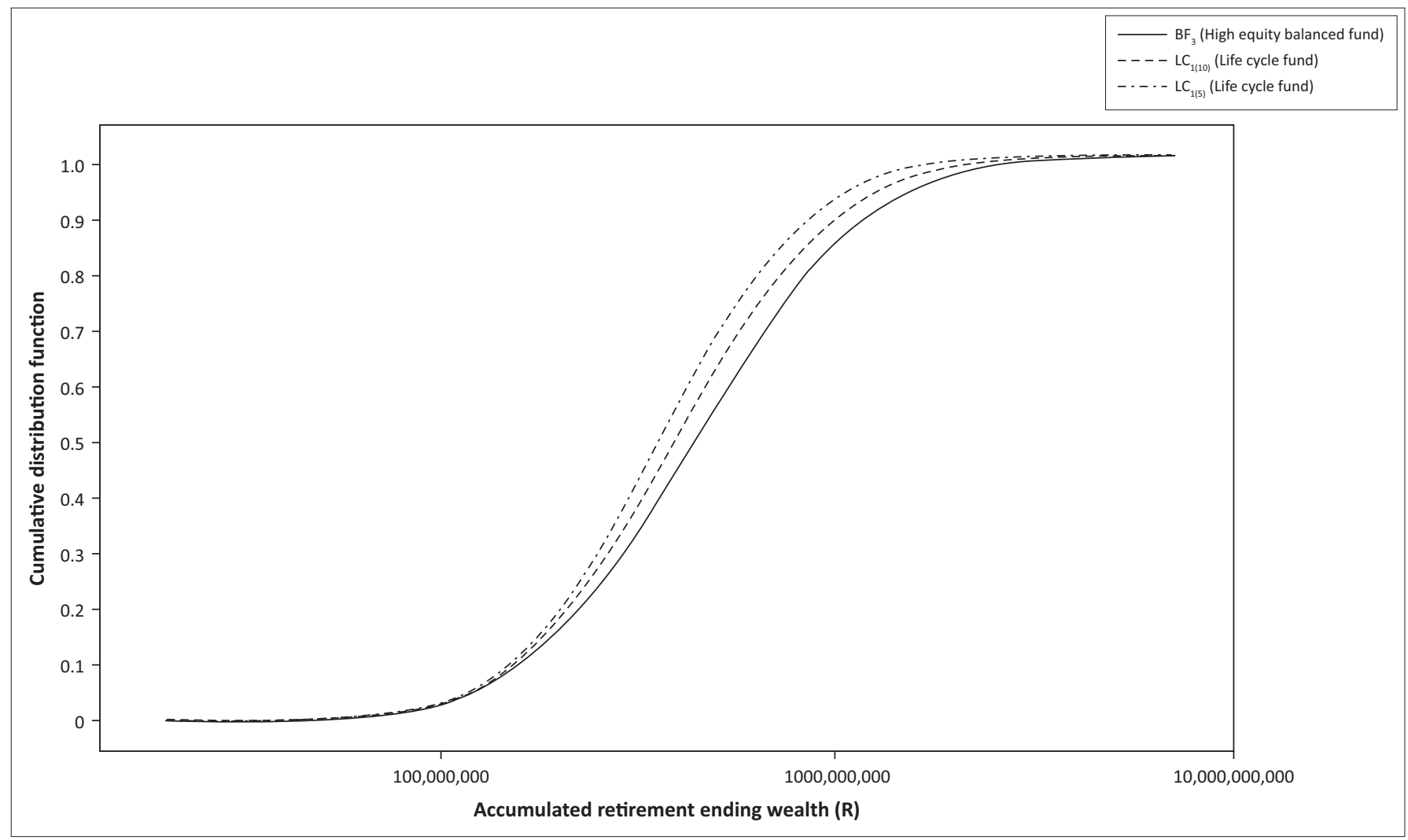

FIGURE 1: Cumulative distribution functions of accumulated retirement ending wealth for models $\mathrm{LC}_{1(10)}$ and $\mathrm{LC}_{1(5)}$ against model $\mathrm{BF}_{3}$.

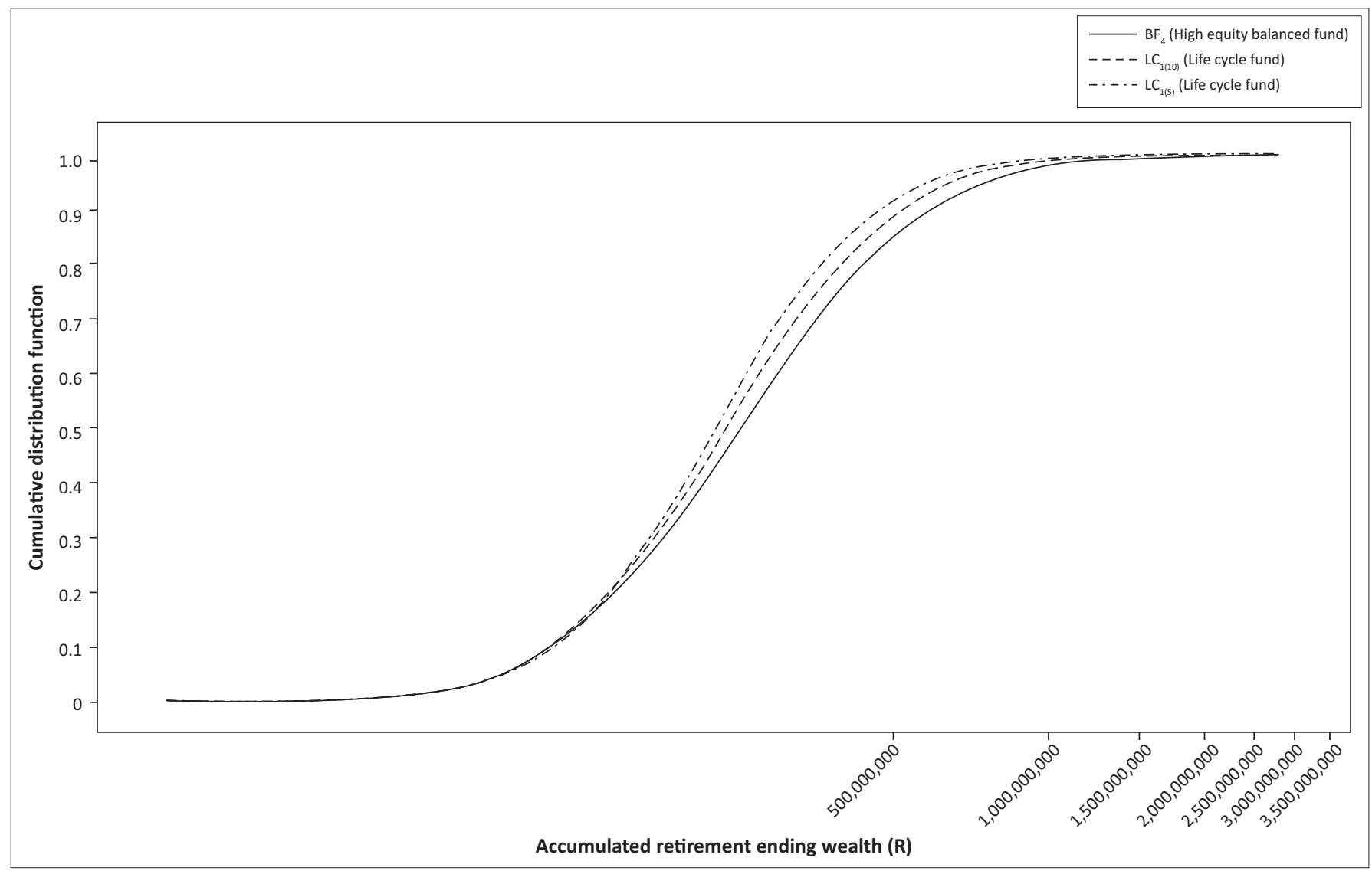

FIGURE 2: Cumulative distribution functions of accumulated retirement ending wealth for models $\mathrm{LC}_{2(10)}$ and $\mathrm{LC}_{2(5)}$ against Model $\mathrm{BF}_{4}$. 
approximately R111.9 million. To the left of R111.9 million, the cumulative distribution function of $\mathrm{LC}_{1(5)}$ is below or to the right of $\mathrm{BF}_{3}$, therefore for an accumulated retirement ending wealth value below R111.9 million, an individual should prefer $\mathrm{LC}_{1(5)}$ as this model is likely to achieve a higher accumulated retirement ending wealth for each cumulative probability versus $\mathrm{BF}_{3}$. However, an individual with a retirement target of more than R111.9 million should prefer $\mathrm{BF}_{3}$ as, in these instances the cumulative distribution function of $\mathrm{BF}_{3}$ is below or to the right of $\mathrm{LC}_{1(5)}$. However, because the area enclosed by the cumulative distribution functions which is to the right of R111.9 million is much larger than the area enclosed to the left, the cumulative distribution functions indicate that $\mathrm{BF}_{3}$ is more likely to dominate $\mathrm{LC}_{1(5)}$ by ASD if the $\varepsilon$ value is between 0 and 0.01 .

Similarly, in Figure 2, the cumulative distribution functions of the life cycle models, $\mathrm{LC}_{2(10)}$ and $\mathrm{LC}_{2(5)^{\prime}}$ cross that of the balanced fund model $\mathrm{BF}_{4}$, also violating the strict $\mathrm{FSD}$ principles. Similar to the case with $\mathrm{LC}_{1(10)}$ and $\mathrm{LC}_{1(5)}$ versus $\mathrm{BF}_{3^{\prime}}$ there is only a small area where $\mathrm{LC}_{2(10)}$ and $\mathrm{LC}_{2(5)}$, respectively, versus $\mathrm{BF}_{4}$ seems optimal which suggest that the life cycle funds are unlikely to dominate the balanced fund by ASD.

Table 3 shows the $\varepsilon$ values for models $\mathrm{LC}_{1(10)^{\prime}}, \mathrm{LC}_{1(5)}, \mathrm{LC}_{2(10)}$ and $\mathrm{LC}_{2(5)}$ against the applicable balanced fund models $\left(\mathrm{BF}_{3}\right.$ and $\mathrm{BF}_{4}$, respectively). In all instances, the $\varepsilon$ values to test for ASD of the LC funds against the BF are much higher than the threshold value of 0.01 , that is, in no instances the LC funds dominate the $\mathrm{BF}$. As this is the case, the table also indicates the instances where the balanced funds dominate the life cycle funds by FSD or ASD with the symbol ' $\$$ ' $\left(\mathrm{BF}_{3}\right.$ dominates both $\mathrm{LC}_{1(10)}$ and $\mathrm{LC}_{1(5)}$ by $\mathrm{ASD}$ and $\mathrm{BF}_{4}$ dominates $\left.\mathrm{LC}_{2(5)}\right)$. The test for dominance of the $\mathrm{BF}$ over the $\mathrm{LC}$ funds requires a comparison of the inverse $\varepsilon$ values shown in the table to the threshold value of 0.01 . As rounding could affect the outcome of test for dominance of the balance funds over the LC funds, it was deemed prudent to, similarly to Basu et al. (2011), round all $\varepsilon$ values to four decimal places.

A further analysis of the result shows that the long glide path of $\mathrm{LC}_{1(10)}$ and $\mathrm{LC}_{2(10)}$ is an important factor in the inability of the life cycle fund models to dominate the balanced fund models. Although the longer glide path provides greater downside risk protection, the upside potential is, however, significantly limited. The results indicate that the longer the glide path, the lower the area of SD violation relative to nonviolation, all other factors held constant. Another matter to consider is the impact of the risk and return characteristics of the asset classes invested on the possibility of whether a LC fund is likely to dominate a balanced fund with similar starting asset allocation by FSD or ASD as the volatility of the asset classes will influence the range of potential accumulated retirement ending wealth values.

\section{Funds with dissimilar starting asset allocations}

To consider the potential SD of life cycle funds versus balanced funds with dissimilar starting asset allocations, life cycle fund models $\mathrm{LC}_{1(10)}$ and $\mathrm{LC}_{1(5)}$ are compared against balanced fund models $\mathrm{BF}_{1}, \mathrm{BF}_{2}$ and $\mathrm{BF}_{4}$, respectively and life cycle fund models $\mathrm{LC}_{2(10)}$ and $\mathrm{LC}_{2(5)}$ are compared against $\mathrm{BF}_{1^{\prime}}$ $\mathrm{BF}_{2}$ and $\mathrm{BF}_{3}$, respectively. The comparative cumulative distribution functions are shown in Figures 3 and 4 with the ASD results shown in Table 4.

In Figure 3, the cumulative distribution functions of life cycle fund models $\mathrm{LC}_{1(10)}$ and $\mathrm{LC}_{1(5)}$ are compared against balanced fund models $\mathrm{BF}_{1}, \mathrm{BF}_{2}$ and $\mathrm{BF}_{4}$ while Figure 4 shows the cumulative distribution functions of life cycle fund models $\mathrm{LC}_{2(10)}$ and $\mathrm{LC}_{2(5)}$ compared against balanced fund models $\mathrm{BF}_{1}, \mathrm{BF}_{2}$ and $\mathrm{BF}_{3}$ with the $\mathrm{FSD}$ and $\mathrm{ASD}$ results presented in Table 4.

Table 4 shows the $\varepsilon$ values to test for dominance of the LC funds over the BF. The table also indicates the instances where BF dominate LC funds by FSD or ASD with the symbol ' $\mathbb{I}$ '. Models $\mathrm{LC}_{1(10)}$ and $\mathrm{LC}_{1(5)}$ successfully dominate all the balanced fund models which have a dissimilar starting asset allocation $\left(\mathrm{BF}_{1}, \mathrm{BF}_{2}\right.$ and $\left.\mathrm{BF}_{4}\right)$. For life cycle fund model $\mathrm{LC}_{1(5)}$ against models $\mathrm{BF}_{2}$ and $\mathrm{BF}_{4}$ there is no $\mathrm{SD}$ violation area, resulting in Model $\mathrm{LC}_{1(5)}$ and $\mathrm{LC}_{1(10)}$ dominating models $\mathrm{BF}_{2}$ and $\mathrm{BF}_{4}$ by FSD. This indicates that the lower risk and return characteristics of the $\mathrm{BF}$ significantly change the cumulative distribution functions of the BF to such an extent that the particular LC fund successfully dominates the BF by ASD.

Life cycle fund model $\mathrm{LC}_{2(10)}$ does not dominate any of the balanced fund models by FSD or ASD $\left(\mathrm{BF}_{1}, \mathrm{BF}_{2}\right.$ and $\left.\mathrm{BF}_{3}\right)$. Rather, there are instances where the opposite is true, namely a balanced fund dominating the life cycle fund by FSD or ASD $\left(\mathrm{BF}_{3}\right.$ dominating $\left.\mathrm{LC}_{2(10)}\right)$. As the ASD results indicate, life cycle fund model $\mathrm{LC}_{2(5)}$ also fails to dominate any of the BF by FSD or ASD. Similarly, there is an instance where a balanced fund $\left(\mathrm{BF}_{3}\right)$ dominates life cycle fund model $\mathrm{LC}_{2(5)}$.

The results indicate that the nature of the different starting asset allocations of a LC fund compared with a balanced fund is an important characteristic, which influences whether a particular fund could dominate the other by FSD or ASD. Additionally, the risk and return characteristics of the asset classes invested in play an important role in whether a particular fund is likely to dominate another as it influences the range of potential accumulated retirement ending wealth values.

\section{Discussion}

\section{Dominance of life cycle funds over balanced funds: Similar starting asset allocations}

Irrespective of the glide path, the LC funds fail to dominate their balanced fund counterparts. Had Basu et al. (2011) also considered this case, it would have been valuable to compare their results with that of this study. However, the focus was on comparing the dynamic LC fund strategy with the traditional LC and balanced fund strategies and not the latter two with each other. In all instances, the cumulative 


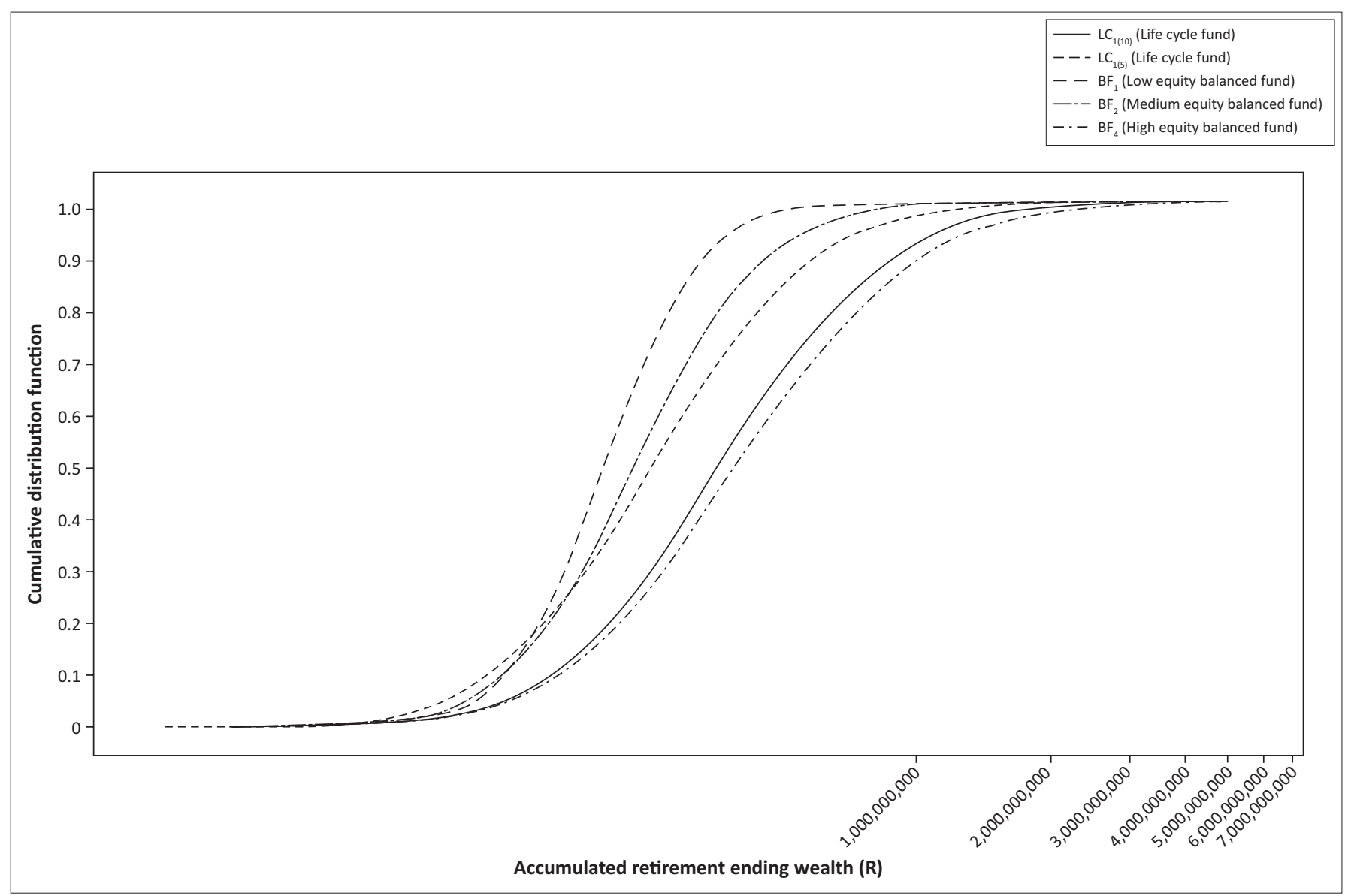

FIGURE 3: Cumulative distribution functions of accumulated retirement ending wealth for models $\mathrm{LC}_{1(10)}$ and $\mathrm{LC}_{1(5)}$ against models $\mathrm{BF}_{1}, \mathrm{BF}_{2}$ and $\mathrm{BF}_{4}$.

distribution functions of the LC funds are, for the most part, above or to the left of the BF and the $\varepsilon$ values fail to be below the threshold value of 0.01. Importantly, there are some instances where the opposite is true, namely the BF dominate the LC funds by FSD or ASD. Although the studies of Lewis (2008a, 2008b, 2008c); Spitzer and Singh (2011); as well as Estrada (2014) use different methods, they all conclude that the BF lead to superior results versus the LC funds. Based on the FSD and ASD criteria, LC funds do not dominate BF with more persistent higher equity allocations based on the dominance decision-making criteria. Yet, this does not consider the unique characteristics that people may have such as a particular retirement target, which may change the individual preference of one fund over the other.

Where a retirement target rather than ASD is considered, the individual would not be concerned with the entire cumulative distribution function but only with the cumulative distribution function below the retirement target which could change which model or fund would be appropriate for the individual. When comparing LC funds with BF that have similar starting asset allocations, it is likely that because of the lower risk characteristics of LC funds, the LC fund could be appropriate for an individual if they have a very low retirement target. However, if the retirement target becomes quite high and meeting the target is more important than the overall risk of the fund chosen, a balanced fund could be chosen. However, important is the fact that reaching the retirement target becomes the primary driving force.
However, the ASD decision-making criteria, which consider the total cumulative distribution function and not a retirement target, are conclusive that when comparing $\mathrm{BF}$ and LC funds with a similar starting asset allocation, the LC funds fail to dominate the BF. There are some instances where the balanced fund dominates the LC fund though, and in these instances, most individuals would prefer the balanced fund over the LC fund. Similar studies regarding the LC versus balanced fund question consider predominantly LC funds that start with a $100 \%$ equity allocation, which does not provide comparative results to this study. It is important to acknowledge that the risk and return characteristics of the asset classes invested in play an important role in whether a balanced fund or LC fund is likely to dominate the other. Similar to Basu et al. (2011), equities have the highest standard deviation and range of historical returns, followed by fixed income and the money market. In this study, the impact of including some exposure to the lower risk and return foreign equity asset class instead of a greater allocation to local equities (which have a higher risk and return than foreign equities) influenced the results. Hence, the results are very sensitive not only to the asset classes invested in but also to the historical data used, what the assumed local asset classes are and the risk and return characteristics of the asset classes used in the study. Additionally, the simulations for each balanced fund exhibit much lower and higher accumulated retirement ending wealth values compared to the LC funds, resulting 


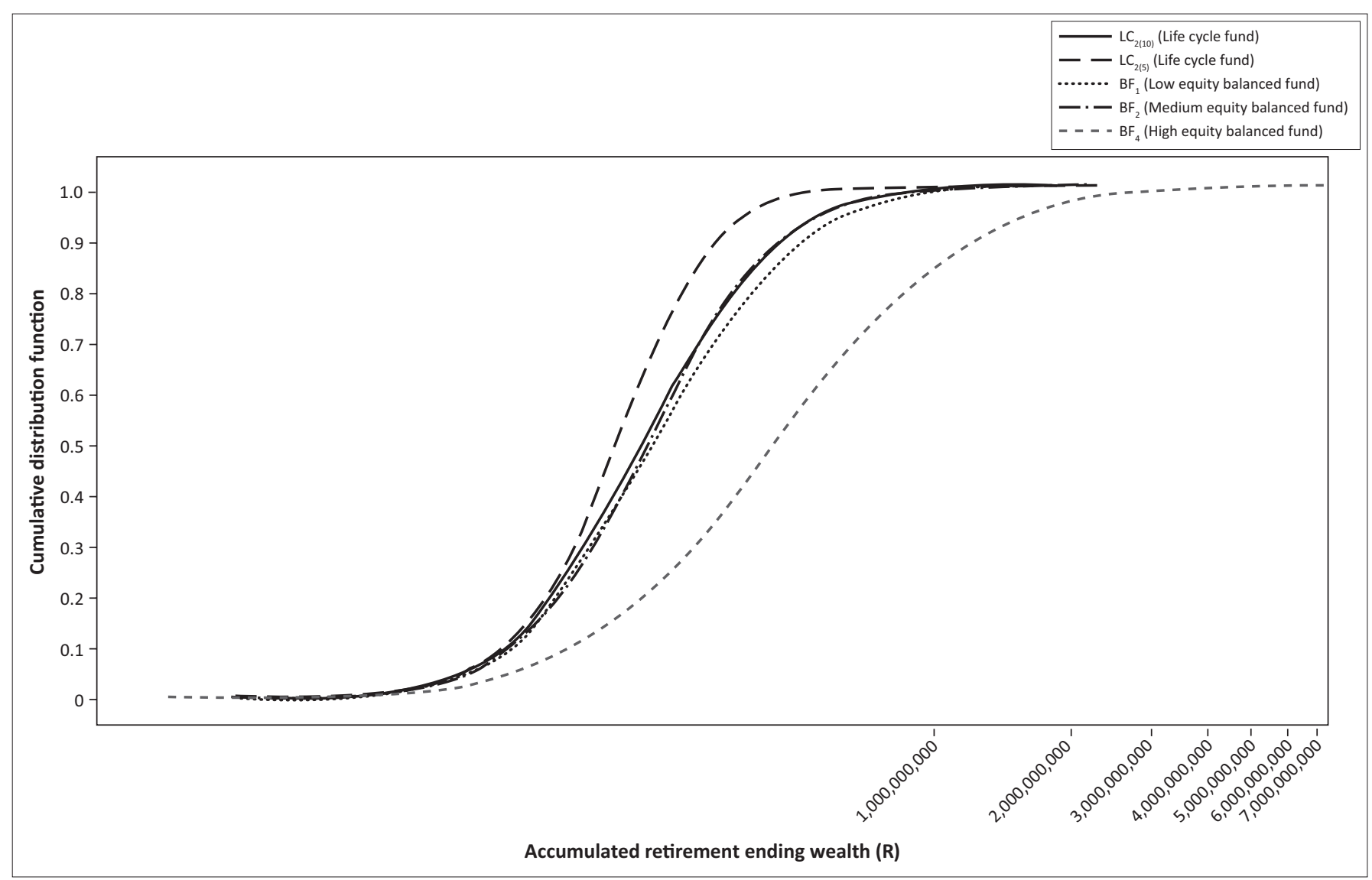

FIGURE 4: Cumulative distribution functions of accumulated retirement ending wealth for models $\mathrm{LC}_{2(10)}$ and $\mathrm{LC}_{2(5)}$ against models $\mathrm{BF}_{1}, \mathrm{BF}_{2}$ and $\mathrm{BF}_{3}$.

TABLE 4: ASD results of life cycle funds against balanced funds - dissimilar starting asset allocation.

\begin{tabular}{|c|c|c|c|c|c|c|c|}
\hline \multirow[t]{2}{*}{ Model } & \multirow[t]{2}{*}{ Balanced fund model } & \multirow{2}{*}{$\begin{array}{l}\text { Beginning asset } \\
\text { allocation } \dagger(\%)\end{array}$} & \multirow{2}{*}{$\begin{array}{c}\text { Glide path } \\
\text { period (years) }\end{array}$} & \multicolumn{4}{|c|}{ Area of SD violation relative to non-violation $(\varepsilon) \$$ : Balanced fund model } \\
\hline & & & & $\mathrm{BF}_{3}(75 / 0 / 15 / 10)$ & $\mathrm{BF}_{4}(50 / 25 / 15 / 10)$ & $\mathrm{BF}_{2}(35 / 25 / 30 / 10)$ & $\mathrm{BF}_{1}(15 / 25 / 50 / 10)$ \\
\hline$\overline{\mathrm{LC}_{1(10)}}$ & Life cycle & $75 / 0 / 15 / 10$ & Final 10 years & - & $0.0000 \S$ & $0.0000 \S$ & $0.0001 \%$ \\
\hline $\mathrm{LC}_{1(5)}$ & Life cycle & $75 / 0 / 15 / 10$ & Final 5 years & - & $0.0000 \S$ & $0.0000 \S$ & $0.0002 \%$ \\
\hline $\mathrm{LC}_{2(10)}$ & Life cycle & $50 / 25 / 15 / 10$ & Final 10 years & 37064.49229 & - & 1.1936 & 0.0208 \\
\hline $\mathrm{LC}_{2(5)}$ & Life cycle & $50 / 25 / 15 / 10$ & Final 5 years & 99009.9009 & - & 0.0644 & 0.0191 \\
\hline
\end{tabular}

$\dagger$, Local equity/foreign equity/local fixed income/local money market; $\ddagger$, Almost stochastic dominance exists for threshold value of $0<\varepsilon<0.01 ; \S$, First-degree stochastic dominance; $\uparrow$, The balanced fund model dominates the life cycle fund model by FSD if $\varepsilon$ value shows 'No value' or ASD in all other cases.

in a much wider range of potential outcomes compared to other studies (see Basu et al. 2011; Estrada 2014; Spitzer and Singh 2011).

\section{Dominance of life cycle funds over balanced funds: Dissimilar starting asset allocations}

The findings indicate that a generalisation regarding dominance of BF and LC funds with dissimilar asset allocation strategies is not possible and mirrors the findings of Spitzer and Singh (2011). In this study, however, life cycle fund Models $\mathrm{LC}_{1(10)}$ and $\mathrm{LC}_{1(5)}$, which have no foreign equity exposure, dominate by ASD or FSD in most instances, while life cycle fund Models $\mathrm{LC}_{2(10)}$ and $\mathrm{LC}_{2(5)^{\prime}}$ which have some foreign equity exposure, in all instances fail to dominate the BF.

The findings seem to indicate that the results are very sensitive to the following characteristics of the models: starting asset allocation, length of the LC glide path and risk and return characteristics of asset classes. As to the starting asset allocation, all other factors held constant, the greater the exposure of a LC fund to the higher risk and return equity asset classes compared with the balanced fund, the more likely the LC fund could dominate by FSD or ASD.

Generalisations with regard to the impact of the glide path are not meaningful as the results are mixed. Lastly, the risk and return characteristics of the asset classes invested in play an important role in whether a balanced fund or LC fund is likely to dominate the other. In this study, the impact of including some exposure to the lower risk and return foreign equity asset class instead of a greater allocation to local equities (which have higher risk and return than foreign equities) influenced the results; although it can be argued that inclusion of foreign equity adds diversification benefits as Mjebeza (2016) suggests, this study showed that the inclusion thereof did not create a more favourable accumulated retirement ending wealth distribution for the applicable models compared to those funds that excluded the foreign equity asset class. 


\section{Impact of the glide path}

A glide path for a LC fund seems to play a significant role in the inability of LC funds to dominate the BF when they have similar starting asset allocations similar to the findings of Basu et al. (2011). The longer the glide path, the greater the downside risk protection provided by a LC fund. However, because of the cumulative nature of the accumulated retirement ending wealth problem, the upside potential is significantly capped, which has a noticeable impact, especially for the longer investment horizons.

\section{Risk and return characteristics of asset classes}

The risk and return characteristics of the asset classes invested in play an important role in whether a balanced fund or LC fund is likely to dominate the other. While the balanced fund represented by balanced fund model $\mathrm{BF}_{4}$ which has a foreign equity allocation, could not dominate the LC fund models with a similar starting asset allocation by FSD or ASD, this was not the case for the life cycle versus balanced pairs that had no allocation to foreign equity and similar starting asset allocations. The impact of the asset class characteristics was even more obvious with regard to the findings pertaining to $\mathrm{LC}$ and $\mathrm{BF}$ with dissimilar starting asset allocations where the extent of foreign equity exposure in the models had a significant impact on whether a LC fund could dominate the other by FSD or ASD.

None of the current works of literature demonstrate this finding as it only considers US asset classes (Basu et al. 2011; Pfau 2010; Spitzer and Singh 2011). This finding also indicates that SD results for comparative studies regarding LC funds as opposed to BF are most likely to yield very different results depending on the historical data used, what the assumed local asset classes are and the risk and return characteristics of those asset classes.

\section{Conclusion}

Saving for retirement is a South African and global challenge; however, research in South Africa on the impact of asset class decisions is limited. In addition, a research contribution that focuses on how to protect retirement funds while facilitating sufficient accumulated retirement ending wealth is valued by the industry and individuals alike.

The study shows how the risk-reducing attributes of LC strategies impact the accumulated retirement ending wealth compared with balanced funds and which choice would be appropriate for most individuals. Because LC funds are a fast-growing portion of the retirement fund market and becoming more popular as default options in retirement funds, this study contributes by statistically contrasting LC funds with balanced funds and by showing that the choice of which fund is optimal is driven by the different characteristics of the funds such as investment horizon, starting and ending asset allocations as well as the length of the glide path.
Retirement fund trustees, investment committees and sponsors must take great care regarding the default funds (life cycle and balanced) that are offered to individuals and, while considering that some individuals may have very specific needs, be careful not to create default options that are sub-optimal. In this study, life cycle funds were shown, in many instances, to fail to represent a better choice for most individuals. Additionally, investor education on the characteristics of different investment choices as well as the implications on accumulated retirement ending wealth will be beneficial in facilitating individual decision-making. Further research in this area that model dynamic life cycle strategies and use expected returns will be valuable.

\section{Acknowledgements}

The authors would like to thank Mr Sollie Millard from the Department of Statistics, University of Pretoria, South Africa.

\section{Competing interests}

The authors declare that they have no financial or personal relationships that may have inappropriately influenced them in writing this article.

\section{Authors' contributions}

E.L. was responsible for the analysis and results. All three authors contributed to the literature review and the interpretation of the results.

\section{References}

Basu, A.K., Byrne, A. \& Drew, M.E., 2011, 'Dynamic lifecycle strategies for target date retirement funds, Journal of Portfolio Management 37, 83-96. https://doi. org/10.3905/jpm.2011.37.2.083

Basu, A.K. \& Drew, M.E., 2009, 'Portfolio size effect in retirement accounts: What does it imply for lifecycle asset allocation funds?', Journal of Portfolio Management 35 61-72. https://doi.org/10.3905/JPM.2009.35.3.061

Bodie, Z., Marcus, A.J. \& Merton, R.C., 1988, 'Defined benefit versus defined contribution pension plans: What are the real trade-offs?', in Z. Bodie, J.B. Shoven \& D.A. Wise (eds.), Pensions in the US Economy, University of Chicago Press, Chicago, IL.

Branch, B. \& Qiu, L., 2011, 'Exploring the pros and cons of target date funds', Financia Services Review 20, 95-111.

Brinson, G.P., Hood, L.R. \& Beebower, G.L., 1986, 'Determinants of portfolio performance', Financial Analysts Journal 42, 39-44. https://doi.org/10.2469/faj. v42.n4.39

Byrne, A., Blake, D., Cairns, A. \& Dowd, K., 2006, 'There's no time like the present: The cost of delaying retirement saving', Financial Services Review 15, 213-231.

Department for Work and Pensions, 2012, Estimates of the number of people facing inadequate retirement incomes, [Online], viewed 15 August 2014, from https:// www.gov.uk/government/uploads/system/uploads/attachment_data/file/223015/ inadequate_retirement_incomes_july2012.pdf

De Villiers-Strydom, J. \& Krige, N., 2014, 'Comparing South African annuity options at retirement', Journal of Economic and Financial Sciences 7, 433-450.

Ervin, D.M., Faulk, G.K. \& Smolira, J.C., 2009, 'The impact of asset allocation, savings, and retirement horizons, savings rates, and social security income in retirement planning: A Monte Carlo analysis', Financial Services Review 18, 313-331.

Estrada, J., 2014, 'The Glidepath illusion: An international perspective', The Journal of Portfolio Management 40, 52-64.

Financial Services Board, 2015a, 2015 Annual report of the registrar of pension funds [Online], viewed 07 March 2017, from https://www.fsb.co.za/Departments/ retirementFund/Documents/Registrar\%20 of\%20Pension $\% 20$ Funds $\% 20$ Annual\%20Report\%202015.pdf

Financial Services Board, 2015b, Annual Report 2015 [Online], viewed 07 March 2015 from https://www.fsb.co.za/departments/communications/documents/fsb\%20 annual\%20report \%202015.pdf

Firer, C. \& McLeod, H., 1999, 'Equities, bonds, cash and inflation: Historical performance in South Africa 1925-1998', Investment Analysts Journal 50, 7-28. 
Firer, C. \& Staunton, M., 2002, '102 years of South African financial market history', Investment Analysts Journal 56, 57-65.

Graves, S.B. \& Ringuest, J.L., 2009, 'Probabilistic dominance criteria for comparing uncertain alternatives: A tutorial', Omega 37, 346-357. https://doi. org/10.1016/j.omega.2007.03.001

Jones, S., 2011, 'Can pensioners save for their pension? You betcha!: Tax', Personal Finance Newsletter, [Online], 362, Sabinet Online: SA ePublications, viewed 15 August 2012, from http://journals.co.za/content/monpf/2011/362/EJC77942

Kemp, S., 2005, 'Getting ready for retirement: Retirement', Personal Finance Newsletter [Online], 291, Sabinet Online: SA ePublications, viewed 15 Augus 2012, from http://journals.co.za/content/monpf/2005/291/EJC76963

Levitan, S. \& Merton, R., 2015, Defined-contribution retirement fund investment strategies: An appropriate default?, Actuarial Society of South Africa, Sandton.

Levy, M., 2009, 'Almost stochastic dominance and stocks for the long run', European Journal of Operational Research 194, 250-257. https://doi.org/10.1016/j. ejor.2007.12.017

Levy, M., 2012, 'Almost stochastic dominance and efficient investment sets', American Journal of Operations Research 2, 313-321. https://doi.org/10.4236/ ajor.2012.23038

Lewis, N.D., 2008a, 'Assessing shortfall risk in life-cycle investment funds', Journal of Wealth Management 11, 15-19. https://doi.org/10.3905/jwm.2008.706261

Lewis, N.D., 2008b, 'Making ends meet: Target date investment funds and retirement wealth creation', Pensions: An International Journal 13, 130-135. https://doi. org/10.1057/pm.2008.18

Lewis, N.D., 2008c, 'The relationship between target date and target risk funds', Pensions: An International Journal 13, 55-60.

Mjebeza, A., 2016, 'Asset allocation and Regulation 28', Masters of Commerce Minidissertation, University of Cape Town, Cape Town.

National Institute on Retirement Savings, 2013, The retirement savings crisis: Is it worse than we think? [Online], Washington, DC, viewed 10 October 2015, from $\mathrm{http}: / /$ www.nirsonline.org/index.php?option=com_content\&task=view\&id=768 \&ltemid $=48$
National Treasury of South Africa, 2011, Pension Funds Act, 1956: Amendment of Regulation 28 of the regulation made under Section 36, Government Gazette, South Africa.

Pang, G. \& Warshawsky, M., 2011, 'Target-date and balanced funds: Latest market offerings and risk-return analysis', Financial Services Review 20, 21-34.

Pfau, W.D., 2010, 'Lifecycle funds and wealth accumulation for retirement: Evidence for a more conservative asset allocation as retirement approaches', Financia Services Review 19, 59-74.

Pfau, W.D., 2011, 'The portfolio size effect and lifecycle asset allocation funds: A different perspective', The Journal of Portfolio Management 37, 44-53. https:// doi.org/10.3905/jpm.2011.37.3.044

Reyers, M., Van Schalkwyk, C.H. \& Gouws, D.G., 2015, 'Rational and behavioural predictors of pre-retirement cash-outs', Journal of Economic Psychology 47, 23-33. https://doi.org/10.1016/j.joep.2015.01.005

Schleef, H.J. \& Eisinger, R.M., 2007, 'Hitting or missing the retirement target: Comparing contribution and asset allocation schemes of simulated portfolios', Financial Services Review 16, 229-243.

Shiller, R.J., 2006, 'Life-cycle personal accounts proposal for social security: An evaluation of President Bush's proposal', Journal of Policy Modeling 28, 427-444. https://doi.org/10.1016/j.jpolmod.2005.10.010

Spitzer, J.J. \& Singh, S., 2008, 'Shortfall risk of target-date funds during retirement', Financial Services Review 17, 143.

Spitzer, J.J. \& Singh, S., 2011, 'Assessing the effectiveness of lifecycle (target-date) funds during the accumulation phase', Financial Services Review 20, 327.

Staunton, M., 2013, e-mail, 07 August, mstaunton@london.edu

Thaler, R.H. \& Benartzi, S., 2007, The behavioral economics of retirement savings behavior, AARP Public Policy Institute, Washington, DC.

Van Heerden, J. \& Koegelenberg, F., 2013, 'Optimal asset allocation strategies for South African pension funds', Studies in Economics and Econometrics 37, 29-54.

Van Zyl, N. \& Van Zyl, D., 2016, 'The impact of behavioural economics and finance on retirement provision', South African Actuarial Journal 16, 91-125. https://doi. org/10.4314/saaj.v16i1.4 